\title{
Growth and endocrine function after treatment for medulloblastoma
}

\author{
I H BROWN, $T$ J LEE, O B EDEN, J A Bullimore, AND D C L SAVAGE \\ The Royal Hospital for Sick Children and the Radiotherapy Centre, Bristol Royal Infirmary, Bristol
}

\begin{abstract}
SUMMARY Children with medulloblastoma in Bristol are treated surgically and with craniospinal irradiation, and in some cases chemotherapy. Thirteen medium or long term survivors were investigated to determine their growth and endocrine function. Their rate of growth was considerably reduced through the first year of their illness and after spinal irradiation spinal growth was poor. Nine children developed growth hormone deficiency. They were clinically euthyroid but 7 had raised basal thyroid stimulating hormone values. Gonadal function was abnormal in all but the youngest child. The rate of survival is increasing in children with medulloblastoma but this is associated with appreciable endocrine abnormalities. Some of these problems are present shortly after treatment ends but others may develop later and long term surveillance is therefore essential.
\end{abstract}

Cerebral tumours are the second most common malignancy of childhood and a quarter of these are medulloblastomas. ${ }^{1}$ The survival of children with medulloblastomas has improved with better surgical and radiotherapeutic techniques ${ }^{2} 3$ but treatment may cause complications and some children present later with growth failure and endocrine dysfunction..$^{4-6}$ The frequency of these problems is unknown. We report the incidence of delayed growth, disorders of sexual maturation, and endocrine dysfunction in the medium and long term survivors among those children treated in Bristol since 1969.

\section{Patients and methods}

The age of diagnosis of the 13 children ranged from 4.7 to 13.3 years (mean 9.9 years) (Table). All the children except 1 had complete or partial removal of the tumour. Radiotherapy was from a cobalt 60 source. It consisted of $50-55 \mathrm{~Gy}(1 \mathrm{~Gy}$ $=100 \mathrm{rad}$ ) to the tumour and $30-35 \mathrm{~Gy}$ to the brain and spinal column given in $20-40$ fractions over 5-8 weeks, except in the patient in case 1 who received $45 \mathrm{~Gy}$ to the tumour and $33 \mathrm{~Gy}$ to the spine. The pituitary hypothalamic axis was judged to have received between 41.7 and $48.6 \mathrm{~Gy}$. Radiotherapy was given in a standard manner from 2 lateral fields with beam shaping using lead blocks and direct posterior fields to the spine. Reduced fields were used to give a high dose to the tumour site.

Four patients received adjuvant chemotherapy. Three had vincristine and 1-(2-chloro-thyl)-3cyclohexyl-1-nitrosurea (CCNU) at 4 weekly inter- vals for 12 months according to the International Society of Paediatric Oncology (SIOP) protocol. One had vincristine, procarbazine, and CCNU at $Q \vec{\circ}$ weekly intervals for 18 months according to the United Kingdom Children's Cancer Study Grou但 (UKCCSG) protocol.

The children's age at endocrine investigation ranged from 6.4 to 15.3 years (mean 12.4 years). No child was investigated less than 16 months from the end of treatment. Staging of puberty and skeletal age were according to described methods. ${ }^{78}$ Anterior pituitary function was tested as described, 9 except in the patient in case 2 where a separate insulin hypoglycaemia and thyrotrophin releasing hormone (TRH) stimulation test was performed and a gonadatrophin releasing hormorne (GnRH) test was not done. Prepubertal children with skeletal ages of 8 to 10 years were primed with sex steroids before assessing their growth hormone $(\mathrm{GH})$ production. ${ }^{10}$ Hormones were measured by radioimmunoassay as described and the results compared with our values for normal children. ${ }^{9}$

\section{Results}

Growth and pubertal development. The longitudinal growth charts are shown in Fig. 1. Heights were not available for the children in cases 1 and 4 during the first year of their illness. In the remainder the height increase in the year after diagnosis was always less than $3 \mathrm{~cm}$. In none of the children was subsequent overall growth normal, for spinal 
Table Details of children with medulloblastoma

\begin{tabular}{|c|c|c|c|c|c|c|c|c|c|c|c|c|c|}
\hline \multirow[b]{2}{*}{$\begin{array}{l}\text { Case } \\
\text { No }\end{array}$} & \multirow[b]{2}{*}{ Sex } & \multicolumn{3}{|c|}{ Diagnosis } & \multicolumn{9}{|c|}{ Endocrine investigation } \\
\hline & & $\begin{array}{l}\text { Age } \\
(y r)\end{array}$ & Puberty & Treatment* & $\begin{array}{l}\text { Age } \\
(y r)\end{array}$ & $\begin{array}{l}\text { Bone } \\
\text { age } \\
(y r)\end{array}$ & Puberty & $\begin{array}{l}\text { Sitting } \\
\text { height } \\
\text { SD score } \\
(\mathrm{cm})\end{array}$ & $\begin{array}{l}\text { GH } \\
\text { peak } \\
(N>15 \\
m U / l)\end{array}$ & $\begin{array}{l}T S H \\
\text { basal } \\
(N<2-4 \\
m U / l)\end{array}$ & $\begin{array}{l}T 4 \\
\text { basal } \\
(N 70-160 \\
\text { nmol/l })\end{array}$ & $\begin{array}{l}\text { LH basal } \\
\text { (prepubertal } \\
N<4 \text { U/l) } \\
\text { (pubertal } \\
N<10 \text { U/l) }\end{array}$ & $\begin{array}{l}\text { Prolactin } \\
\text { basal } \\
(N 40-360 \\
m U / l)\end{array}$ \\
\hline $\begin{array}{r}1 \\
2 \\
3 \\
4 \\
5 \\
6 \\
7 \\
8 \\
9 \\
10 \\
11 \\
12 \\
13\end{array}$ & $\begin{array}{l}\mathbf{M} \\
\mathbf{F} \\
\mathbf{M} \\
\mathbf{M} \\
\mathbf{F} \\
\mathbf{F} \\
\mathbf{F} \\
\mathbf{M} \\
\mathbf{M} \\
\mathbf{M} \\
\mathbf{M} \\
\mathbf{F} \\
\mathbf{F}\end{array}$ & $\begin{array}{r}7 \cdot 3 \\
11.9 \\
12 \cdot 4 \\
10 \cdot 7 \\
11 \cdot 1 \\
11 \cdot 2 \\
7.6 \\
11.4 \\
7.9 \\
12.9 \\
4.7 \\
7.5 \\
13 \cdot 3\end{array}$ & $\begin{array}{l}\mathbf{P}_{\mathbf{1}} \mathbf{G}_{1} \\
\mathbf{P}_{\mathbf{1}} \mathbf{G}_{1} \\
\overline{-} \\
\overrightarrow{\mathbf{P}_{1} \mathbf{G}_{1}} \\
\mathbf{P}_{\mathbf{1}} \mathbf{G}_{1} \\
\mathbf{P}_{1} \mathbf{G}_{1} \\
\mathbf{P}_{1} \mathbf{G}_{1} \\
\mathbf{P}_{\mathbf{1}} \mathbf{G}_{1} \\
\overrightarrow{\mathbf{P}_{1} \mathbf{G}_{1}} \\
\mathbf{P}_{\mathbf{1}} \mathbf{G}_{1} \\
\mathbf{P}_{\mathbf{4}} \mathbf{G}_{\mathbf{4}}\end{array}$ & $\begin{array}{l}1 \\
1 \\
2 \\
1 \\
1 \\
1 \\
2 \\
1 \\
2 \\
2 \\
1 \\
1 \\
1\end{array}$ & $\begin{array}{r}14 \cdot 5 \\
13.7 \\
14.4 \\
12 \cdot 7 \\
13.5 \\
12 \cdot 5 \\
11 \cdot 3 \\
13 \cdot 1 \\
10.4 \\
15.3 \\
6.4 \\
9 \cdot 1 \\
14.4\end{array}$ & $\begin{array}{r}17 \cdot 8 \\
12 \cdot 3 \\
14 \cdot 8 \\
14 \cdot 6 \\
13.9 \\
10 \cdot 9 \\
11 \cdot 3 \\
11 \cdot 1 \\
9.9 \\
15 \cdot 3 \\
7.8 \\
7 \cdot 1 \\
13.9\end{array}$ & $\begin{array}{l}P_{4} \mathbf{G}_{4} \\
\mathbf{P}_{2} \mathbf{G}_{3} \\
\mathbf{P}_{\mathbf{3}} \mathbf{G}_{4} \\
\mathbf{P}_{2} \mathbf{G}_{4} \\
\mathbf{P}_{2} \mathbf{G}_{4} \\
\mathbf{P}_{1} \mathbf{G}_{1} \\
\mathbf{P}_{1} \mathbf{G}_{1} \\
\mathbf{P}_{1} \mathbf{G}_{1} \\
\mathbf{P}_{1} \mathbf{G}_{1} \\
\mathbf{P}_{\mathbf{8}} \mathbf{G}_{3} \\
\mathbf{P}_{1} \mathbf{G}_{1} \\
\mathbf{P}_{1} \mathbf{G}_{1} \\
\mathbf{P}_{4} \mathbf{G}_{4}\end{array}$ & $\begin{array}{c}-1.11 \\
-1.17 \\
-1.18 \\
-2.51 \\
-3.16 \\
-3.07 \\
-3.39 \\
-1.44 \\
-0.93 \\
-1.61 \\
-1.91 \\
-1.49\end{array}$ & $\begin{array}{r}25.4 \\
6.4 \\
27.2 \\
11.3 \\
5.7 \\
12.5 \\
24.9 \\
13.4 \\
13.6 \\
18 \cdot 8 \\
12 \cdot 1 \\
<1 \\
14.9\end{array}$ & $\begin{array}{l}<2 \\
<2 \\
<2 \\
5 \cdot 8 \\
7 \\
<2 \\
9 \\
<2 \\
9 \\
7 \\
8 \\
7 \\
<2\end{array}$ & $\begin{array}{r}90 \\
180 \\
80 \\
75 \\
88 \\
82 \\
76 \\
92 \\
80 \\
113 \\
89 \\
83 \\
94\end{array}$ & $\begin{array}{l}11 \\
4 \cdot 4 \\
9 \\
14 \cdot 8 \\
2 \\
17 \\
2 \cdot 8 \\
2 \cdot 5 \\
18 \\
<2 \\
3 \cdot 4 \\
15 \cdot 5\end{array}$ & $\begin{array}{l}\bar{Z} \\
\bar{Z} \\
319 \\
490 \\
830 \\
\overline{251} \\
\overline{586} \\
1457 \\
271\end{array}$ \\
\hline
\end{tabular}

$*_{1}=$ Radiotherapy, 2 = radiotherapy and chemotherapy. $\mathbf{N}=$ normal; $\mathbf{G H}=$ growth hormone; TSH $=$ thyroid stimulating hormone, T4 = thyroxin; $\mathbf{L H}=$ luteinising hormone.

Conversion: SI to traditional units—Thyroxine $1 \mathrm{nmol} / 1=0.78 \mu \mathrm{g} / \mathrm{dl}$.

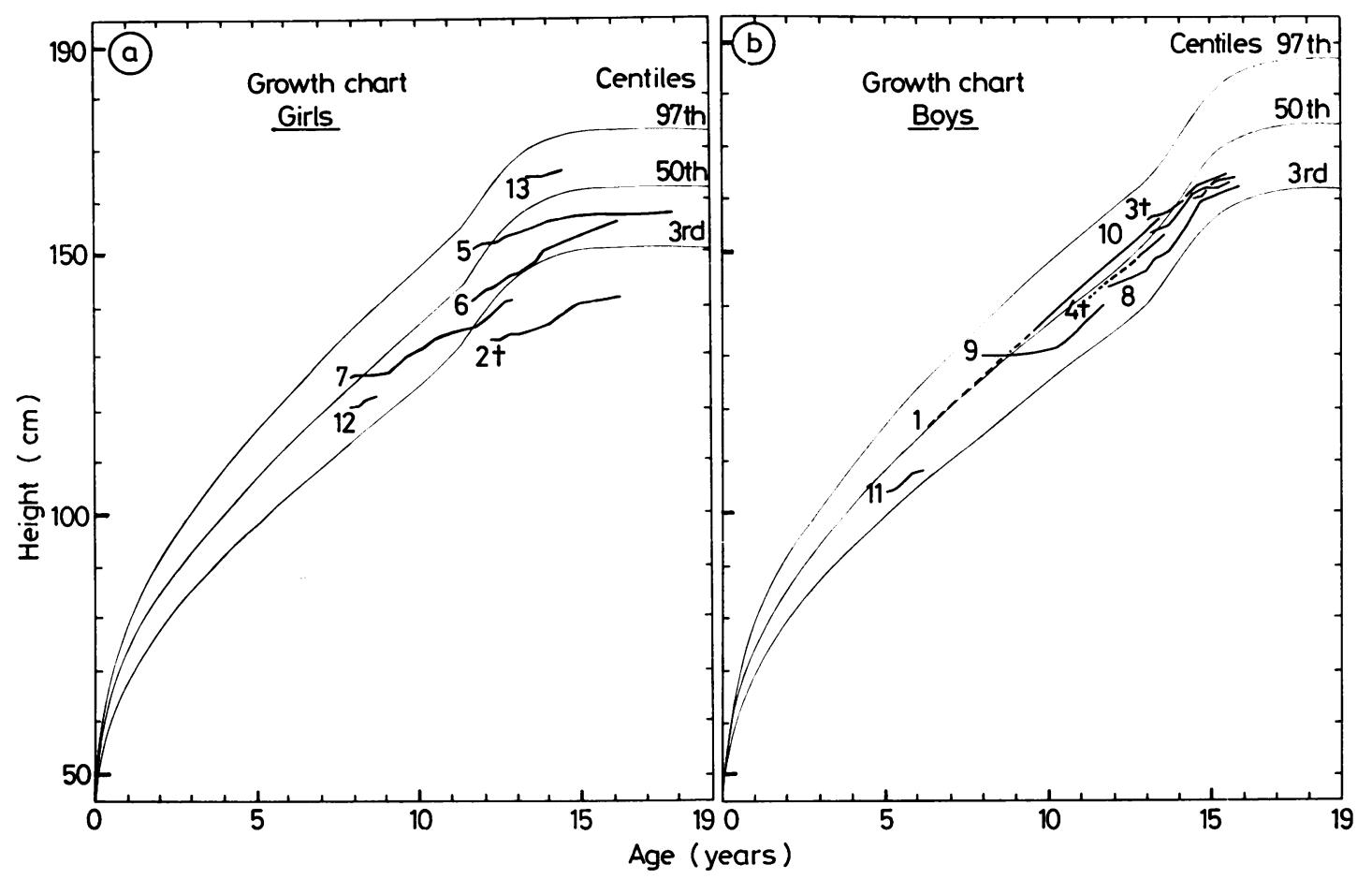

Fig. 1 Longitudinal growth of children treated for medulloblastoma.

growth (not measured in case 2) was uniformly affected with the sitting height standard deviation score ranging from -0.93 to $-3.39 \mathrm{~cm}$ (mean $1.91 \mathrm{~cm}$ ). Puberty was not delayed in the boys, but except in the youngest boy (case 11) the testicles were small for the stage of puberty and felt unusually firm. One girl had delayed puberty (case 7) and in another (case 13) menstruation ceased after treatment. Two girls (cases 5 and 6) who were prepubertal at the start of treatment now have regular periods. None of the children had an appreciable delay in skeletal maturation. 
Growth hormone. The biochemical data are shown in the Table. Four patients had a normal GH response $(\mathrm{GH}>15 \mathrm{mU} / \mathrm{l}), 3$ had $\mathrm{GH}$ deficiency $(\mathrm{GH}<7 \mathrm{mU} / \mathrm{l})$ and 6 patients showed partial $\mathrm{GH}$ deficiency (GH 7-15 mU/l). The absence of GH had a marked effect on the pubertal growth spurt (Fig. 2).

Thyroid and adrenal function. All the children were clinically euthyroid and had normal thyroxine values but the basal thyroid stimulating hormone (TSH) was raised in 7 and they also had excessive TSH responses to thyrotropin releasing hormone (TRH). The basal cortisol values and the cortisol response to insulin hypoglycaemia was normal in all the children.

Prolactin. The basal prolactin concentration was raised in 4 of the 7 children in whom it was measured.

Gonadal function. Six children seemed to be clinically prepubertal but in 2 of them (cases 8 and 9) the luteinising hormone (LH) response to GnRH and their plasma testosterone values showed that they were in early puberty. In the 4 prepubertal children, 2 (cases 6 and 11) had appropriate basal $\mathrm{LH}$ values $(<4 \mathrm{U} / 1), \mathrm{LH}$ responses to $\mathrm{GnRH}$ $(<9 \mathrm{U} / \mathrm{l})$ and gonadal steroid values, but in the other 2,1 (case 7) had a raised basal LH value and both (cases 7 and 12) had inappropriately high responses to GnRH with low gonadal steroid values. In the 6 children who were clinically or biochemically, or both, in puberty, 4 (cases $1,5,10$, and 13) had raised basal $\mathbf{L H}$ values $(>10 \mathrm{U} / \mathrm{l})$ and their $\mathrm{LH}$ responses to GnRH were exaggerated and prolonged
(Table). The basal follicle stimulating hormone (FSH) value was raised (FSH $\sigma^{\dagger}>5 \mathrm{U} / \mathrm{l}, \mathrm{FSH}$ $\uparrow>8 \mathrm{U} / \mathrm{l}$ ) in 8 children (cases $1,3,4,5,7,10,12$, and 13) and they all had exaggerated responses to GnRH. In the remaining 4 with normal baseline FSH values, 3 had exaggerated response to GnRH (Fig. 3). Plasma testosterone and oestradiol con-

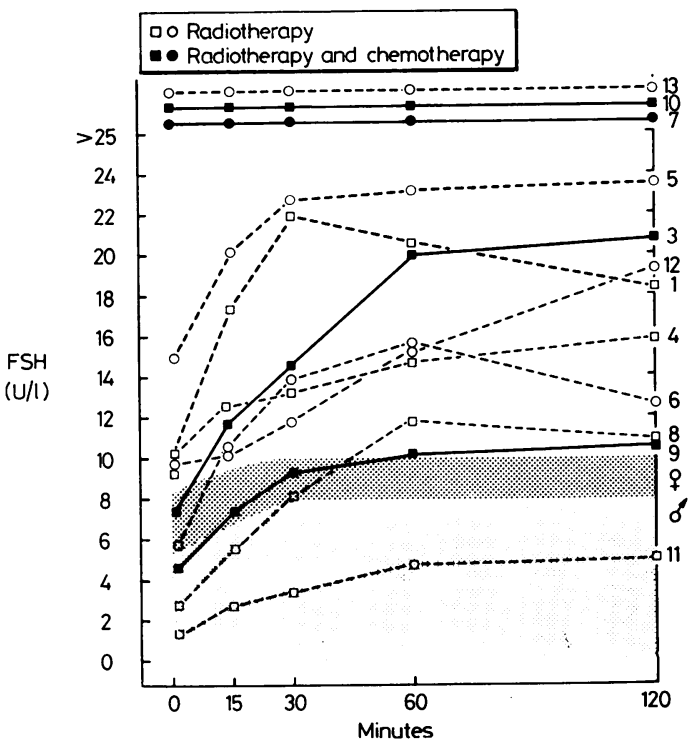

Fig. 3 Medulloblastoma treated patients-follicle stimulating hormone response to gonadotrophin releasing hormone.

\& Maximum response in prepubertal and premenarchal girls maximum response in prepubertal and pubertal boys.

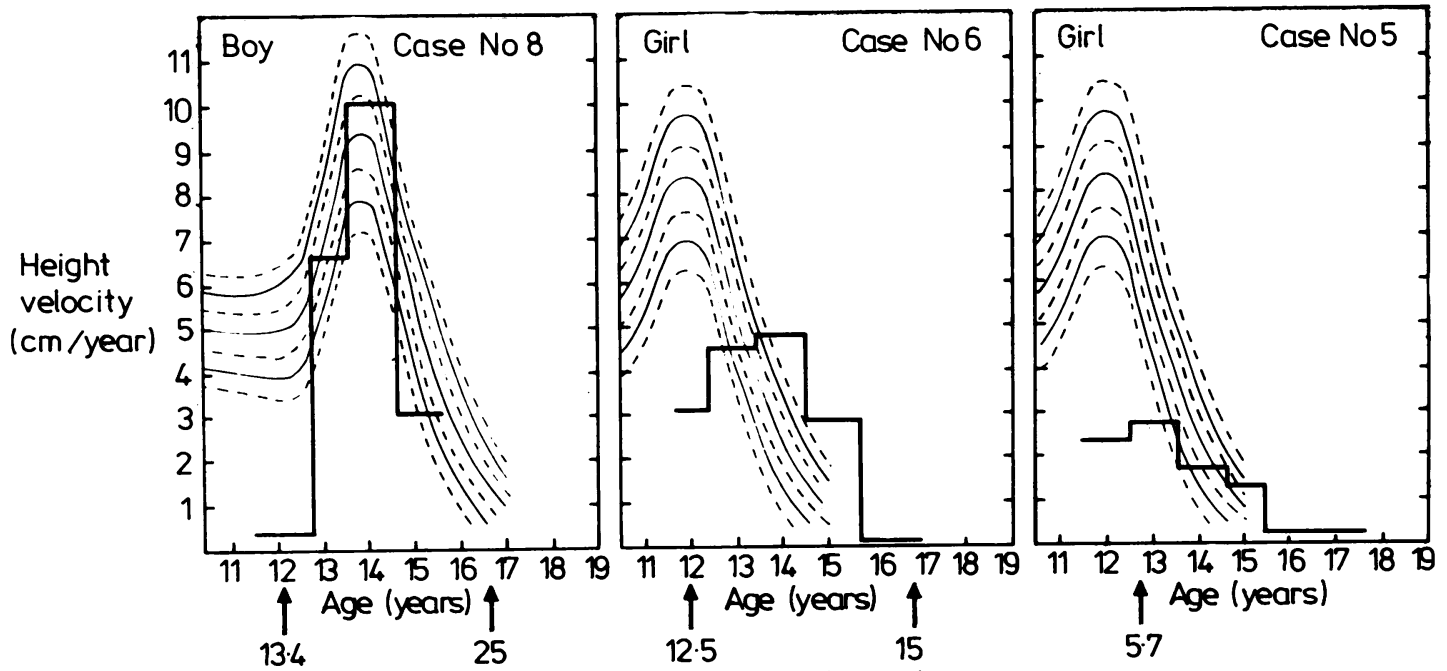

Growth hormone ( $\mathrm{mU} / \mathrm{l})$

Fig. 2 Effect of the presence of growth hormone (case 8) and its partial deficiency (case 6) or complete deficienc (case 5) on height velocity in puberty. Arrows indicate age at which growth hormone concentrations were measured. 
centrations were appropriate for gonadotrophin status except in 2 children (cases 7 and 13) where plasma oestradiols were extremely low at $<30$ $\mathrm{pmol} / \mathrm{l}(<8 \cdot 17 \mathrm{pg} / \mathrm{ml})$.

Posterior pituitary function. No child had clinical evidence of posterior pituitary dysfunction.

\section{Discussion}

We have shown that the survivors of those children treated for medulloblastoma often grow poorly. In the year after diagnosis this may result from ill health and anorexia, though an associated transient GH deficiency is known to occur during or immediately after cranial irradiation. ${ }^{11}$

Our data show that 1 factor in the poor growth is retardation of spinal growth. Two previous series $^{1213}$ did not report this, but others have clearly shown the deleterious effects of spinal irradiation in childhood, particularly during periods of accelerated growth. ${ }^{14}{ }^{15}$ Spinal irradiation damages both the epiphyseal plates and the bony matrix and although cessation of vertebral growth may occur, it usually resumes-often associated with abnormal roentographic findings. ${ }^{16}$

Another cause for the poor growth is GH deficiency. Cranial irradiation which may damage the hypothalamus $^{17}$ is a well recognised cause of this. ${ }^{6}$ Previously doses as high as 6.0 Gy were thought to be relatively safe but Shalet has shown that doses $>2.9$ Gy commonly cause GH deficiency. ${ }^{18}$ The natural history of these children's GH secretion is unknown, though Shalet found that half of those who received appreciable cranial irradiation had become GH deficient 1 year later. ${ }^{19}$ We believe that investigation of GH status should be left for about 18 months to allow other causes of poor growth to resolve, and that the timing of the investigation must depend on the child's rate of growth. Regular monitoring of height and sitting height is essential. At puberty delayed diagnosis has a rapid and profound effect on final height.

The raised basal TSH value and excessive TSH response to TRH indicate primary thyroid dysfunction. Similar results have been described in patients with lymphomas who have received irradiation to the neck, with the patients aged less than 20 years being at greatest risk. ${ }^{20}{ }^{21}$ Raised basal TSH values have also been reported in children with leukaemia who have received craniospinal irradiation..$^{22}$ In all these series the amount of radiation ranged from 20-40 Gy. We have calculated that our children received a radiation dose to the thyroid of between 20-40 Gy depending on individual radiotherapy plans, and this has been confirmed using skin dose meters in 1 patient. The risk of neoplastic change in the thyroid is increased after exposure to radioactive fallout and in children who have received radiotherapy to the neck and mediastinum. ${ }^{24-26}$ Three cases of thyroid carcinoma have been reported 7-12 years after irradiation for medulloblastoma. ${ }^{27} 28$ The raised TSH values in association with the radiation damage to the thyroid may be an important factor in carcinogenesis ${ }^{29}$ and treatment with thyroxine to suppress TSH may be appropriate in these patients.

Hyperprolactinaemia may have resulted from irradiation damage to the hypothalamic neurones that synthesise prolactin inhibiting factor or from the increased TRH that results from primary thyroid damage. ${ }^{30}$ In one child the plasma prolactin values returned to normal with thyroid replacement treatment.

Plasma gonadotrophin values were raised in a number of the children. Raised plasma FSH indicates damage to the germinal cells of the testes or ovary, while raised LH concentrations reflect damage to either the Leydig cells of the testes or the theca cells of the ovary. Changes in FSH are the more sensitive indicator of gonadal damage but the age of the patient and the extent of gonadal damage does modify the response. ${ }^{31} 32$

Our data confirm the difficulty in diagnosing partial gonadal damage in mid-childhood but suggest that in the late prepubertal child the FSH response to $\mathrm{GnRH}$ may be a more sensitive indicator than the basal FSH value alone. The combined clinical and biochemical data indicate that all but the youngest child have damaged gonads, but that with 1 exception gonadal steroid production is sufficient to allow normal sexual maturation. The biochemical data suggest that their fertility has been impaired though the extent of this is as yet unknown. The youngest child as he grows older may show evidence of similar gonadal problems.

The cause of gonadal damage must be irradiation. Chemotherapy may be an additional hazard for the only child who is agonadal (case 7) had combined radiotherapy and chemotherapy. Furthermore, we have other patients who have had CCNU but no spinal radiotherapy who have evidence of primary gonadal damage, and all 3 drugs used in this study are capable of causing this. ${ }^{33}$ Shalet reported ovarian $^{34}$ and testicular ${ }^{35}$ damage after abdominal irradiation in childhood. This is influenced not only by the total radiation dose but also by the fractionation and time sequence of treatment and the sex and age of the patient. In women the population of oocytes is finalised at birth and decreases with age. It is not surprising, therefore, that irradiation damage occurs more frequently in older than younger women. However, single doses of $6 \mathrm{~Gy}$ are probably 
$100 \%$ effective in inducing permanent sterility in women of all ages. ${ }^{36}$ Spermatagonia are more susceptible to irradiation than Leydig cells and doses as low as $0.2 \mathrm{~Gy}$ in adults may cause temporary sterility, although recovery up to 5 years later has followed doses of over $6 \mathrm{~Gy}^{37}$ Whether the quiescent prepubertal testis is more or less vulnerable to irradiation is unknown. In this study, after spinal irradiation of $35 \mathrm{~Gy}$ the scattered dose to the ovaries may be as high as $10 \mathrm{~Gy}$, and by the use of skin dose meters we have calculated a cumulative dose of approximately $2.4 \mathrm{~Gy}$ to the testes.

Prophylactic spinal irradiation is given because of the danger of seeding of medulloblastoma cells to the spine. In 1 study $43 \%$ of the patients presented with spinal cord deposits detected by myelography. ${ }^{38}$ A lower dose of radiaion to the lumbar spine may be as effective and cause less damage to the pelvic organs. Alternatively the use of a linear accelerator producing photon beams with a narrow penumbra rather than 60 Co beams would reduce the scatter dose and thus cause less damage.

These children's survival has increased with advances in treatment but the treatment does damage a number of their endocrine glands. Radiotherapy is the major cause of these complications but combined chemotherapy probably contributes towards some of them. The natural history of this endocrine dysfunction is unknown, and close monitoring of the children's growth and hormonal status is necessary for many years before we can be certain of the long term outcome.

We thank the staff of the laboratories of the Bristol Royal Inflrmary, Southmead Steroid Laboratory and the Tenovus Unit, Cardiff University for the biochemical assays. O B Eden was supported by the Leukaemic Research Fund.

\section{References}

1 Richardson A. Intracranial tumours. In: Rose FC, ed. Paediatric neurology. Oxford:Blackwell Scientific Publications, 1980: 483-96.

2 McIntosh N. Medulloblastoma-a changing prognosis? Arch Dis Child 1979;54:200-3.

3 Berry MP, Jenkin RDT, Keen CW, Nair BD, Simpson WJ. Radiation treatment for medulloblastoma. A 21-year review. J Neurosurg $1981 ; 55: 43-51$.

4 Perry-Keene DA, Connelly JF, Young RA, Wettenhall HNB, Martin FIR. Hypothalamic hypopituitarism following external radiotherapy for tumours distant from the adenohypophysis. Clin Endocrinol $(O x f)$ $1976 ; 5: 373-80$.

5 Richards GE, Wara WM, Greenbach MM, Kaplan SL, Sheline GE, Conte FA. Delayed onset of hypopituitarism: Sequelae of therapeutic irradiation of central nervous system, eye and middle ear tumours. $J$ Pediatr 1976;89: 553-9.

- Shalet SM, Beardwell CG, Morris-Jones PH, Pearson D. Pituitary function after treatment of intracranial tumours in children. Lancet 1975 ; ii:104-7.

7 Tanner JM. Growti and adolescence. Oxford:Blackwell, 1962.
8 Tanner JM, Whitehouse RH, Marshall WA, Healy MJR, Goldstein H. Assessment of skeletal maturity and prediction of adult height (TW2 method). London:Academic Press, 1975.

9 Savage DCL, Swift PGF, Johnston PGB, Goldie DJ, Murphy D. Combined test of anterior pituitary function in children. Arch Dis Child 1978;53:301-4.

10 Preece MA. Growth hormone deficiency. In: Brook CGD, ed. Clinical paediatric endocrinology. Oxford:Blackwell, $1981: 285-304$.

11 Dacou-Voutetakis C, Haidas St, Zannos-Mariolea L. Radiation and pituitary function in children. (letter). Lancet 1975 ; ;i: $1206-7$.

12 Bloom HJG, Wallace ENK, Henk JM. The treatment and prognosis of medulloblastoma in children. $A J R$ 1969; 105:43-62.

13 Landberg TG, Lindgren ML, Cavallin-Stohl EK, et al. Improvements in the radiotherapy of medulloblastoma 1946-1975. Cancer 1980;45:670-8.

14 Probert JC, Parker BR, Kaplan HS. Growth retardation in children after megavoltage irradiation of the spine. Cancer 1973;32:634-9.

15 Broadbent VA, Barnes ND, Wheeler TK. Medullo- N blastoma in childhood:long term results of treatment. Cancer $1981 ; 48: 26-30$.

16 Teft M. Radiation effect on growing bone and cartilage. Front Radiol Ther Oncol 1972;6:259-311.

17 Arnold A. Effects of $x$-irradiation on the hypothalamus: a possible explanation for the therapeutic benefits following $x$-irradiation of the hypophysial region for pituitary dysfunction. J Clin Endocrinol Metab 1954;14:859-68.

18 Shalet SM, Beardwell CG, Pearson D, Morris-Jones PH The effect of varying doses of cerebral irradiation of growth hormone production in childhood. Clin Endocrine (Oxf) 1976;5:287-90.

19 Shalet SM, Beardwell CG, Aarons BM, Pearson Morris-Jones PH. Growth impairment in childre treated for brain tumours. Arch Dis Child 1978;53:491-4.

20 Glatstein E, McHardy-Young S, Brast N, Eltringham JR, Kriss JP. Alterations in serum thyrotropin (TSH) and thyroid function following radiotherapy in patients with malignant lymphoma. J Clin Endocrinol Metab 1971 $32: 833-41$.

21 Shalet SM, Rosenstock JD, Beardwell CG, Pearson D, Morris-Jones PH. Thyroid dysfunction following external irradiation to the neck for Hodgkin's disease in childhood. Clin Radiol 1977;28:511-5.

22 Shalet SM, Beardwell CG, Twomey JA, Morris-Jones PH, Pearson D. Endocrine function following the treatment of acute leukemia in childhood. J Pediatr 1977;90:920-3.

23 Swift PGF, Kearney PJ, Dalton RG, Bullimore JA, Mott MG, Savage DCL. Growth and hormonal status of 8 children treated for acute lymphoblastic leukaemia. Arch Dis Child 1978;53:890-4.

24 Parker LN, Belsky JL, Yamamoto T, Kawamoto S, 을 Keehn RJ. Thyroid carcinoma after exposure to atomic $D$ radiation. Ann Intern Med $1974 ; 80: 600-4$.

25 Refetoff S, Harrison J, Karanfilski BT, Kaplan EL, De Groot LJ, Bekerman C. Continuing occurrence of $\mathrm{N}^{-}$ thyroid carcinoma after irradiation to the neck in infancy and childhood. $N$ Engl J Med $1975 ; 292: 171-5$.

26 Favus MJ, Schneider AB, Stachura ME, et al. Thyroid N cancer occurring as a late consequence of head and neck irradiation. N Engl J Med 1967;294:1019-25.

27 Raventos A, Duszynski DO. Thyroid cancer following $Q$ irradiation for medulloblastoma. AJR 1963;89:175-81

28 Andrew DS, Kerr IF, Carcinoma of thyroid following irradiation for medulloblastoma. Clin Radiol 1965;16: 282-3. 
29 Conard RA, Rall JE, Sutow WW. Thyroid nodules as a late sequela of radioactive fallout. $N$ Engl J Med 1966; 274:1391-9.

30 Kurtz A. Hypophyseal physiology. In: Brook CGD, ed. Clinical paediatric endocrinology. Oxford:Blackwell, $1981: 268$.

31 Conte FA, Grumbach MM, Kaplan SL, Reiter EO. Correlation of luteinizing hormone-releasing factorinduced luteinizing hormone and follicle-stimulating hormone release from infancy to 19 years with the changing pattern of gonadotropin secretion in agonadal patients; relation to the restraint of puberty. J Clin Endocrinol Metab 1980;50:163-8.

32 Winter JSD, Faiman C. Serum gonadotropin concentrations in agonadal children and adults. J Clin Endocrinol Metab $1972 ; 35: 561-4$.

33 Schilsky RL, Lewis BJ, Sherins RJ, Young RC. Gonadal dysfunction in patients receiving chemotherapy for cancer. Ann Intern Med 1980;93:109-14.

34 Shalet SM, Beardwell CG, Morris-Jones PH, Pearson D, Orrell DH. Ovarian failure following abdominal irradiation in childhood. Br J Cancer 1976;33:655-8.

35 Shalet SM, Beardwell CG, Jacobs HS, Pearson D. Testicular function following irradiation of the human prepubertal testis. Clin Endocrinol 1978;9:483-90.

36 Ash $P$. The influence of radiation on fertility in man. Br J Radiol 1980;53:271-8.

37 Rowley MJ, Leach DR, Warner GA, Heller CG. Effect of graded doses of ionizing irradiation on the human testis. Radiat Res 1974;59:665-78.

38 Deutsch M, Reigel DH. The value of myelography in the management of childhood medulloblastoma. Cancer $1980 ; 45: 2194-7$.

Correspondence to Dr D C L Savage, Royal Hospital for Sick Children, St Michael's Hill, Bristol BS2 8RJ

Received 12 May 1983

\section{Commentary}

\section{S M SHALET}

\section{Department of Endocrinology, Christie Hospital, Manchester}

Brown et al. draw attention to a group of children with medulloblastoma in whom treatment has impaired subsequent growth and damaged a number of endocrine glands. Growth hormone (GH) is the first anterior pituitary hormone to be affected by radiation damage to the hypothalamic pituitary axis. A number of groups have described subnormal GH responses to pharmacological stimuli in children irradiated for medulloblastoma. Unfortunately there are no long term studies of the effects of GH treatment in a large number of children with radiation induced GH deficiency. These data are badly needed as GH deficiency is only 1 of a number of factors that may impair growth. ${ }^{1}$ Spinal irradiation modifies spinal growth, while the effects of occult recurrent tumour, chemotherapy, and subtle degrees of thyroid dysfunction on growth are unknown.

Thyroid dysfunction in children treated for medulloblastoma is due to radiation damage to the thyroid. Frank hypothyroidism ( $\uparrow$ thyroid stimulating hormone (TSH) $\downarrow$ thyroxine (T4)) is rare but should, if present, be treated with T4. More frequently a raised serum TSH concentration with a normal serum T4 value may be found in a child who is clinically euthyroid and here treatment with $\mathrm{T} 4$ has also been suggested. It is argued that a raised TSH value is carcinogenic in a child who has previously received irradiation to the thyroid and that a raised TSH value per se indicates that mild hypothyroidism is present. There is, however, only anecdotal evidence that thyroid carcinoma complicates the treatment of medulloblastoma and unless treatment with thyroxine is monitored carefully additional problems may be created rather than resolved.

Rappaport et $a .^{2}$ described delayed onset or impaired progress through puberty in children treated for medulloblastoma. In these children gonadotrophin deficiency, occasionally associated with hyperprolactinaemia, was caused by radiation damage to the hypothalamic pituitary axis. Many of the children studied by Brown et al. also showed evidence of gonadal dysfunction but in these children the gonads were damaged directly by scattered radiation from the spinal field. Finally, Ahmed et al. ${ }^{3}$ described gonadal dysfunction in another group of children treated for medulloblastoma. None of their children had gonadotrophin deficiency cr radiation induced gonadal damage. In these children the aetiological factor was adjuvant chemotherapy with nitrosoureas (BCNU and $\mathrm{CCNU}$ ) that had directly damaged the gonads.

Apart from the practical problem of management of some of these endocrine problems, other questions are raised by these studies. In all groups of children with medulloblastoma do the benefits of adjuvant chemotherapy outweigh the risks and is the current dose of spinal irradiation the minimum required to destroy medulloblastoma cells that have seeded to the spinal meninges? It is possible that if the dose of spinal irradiation could be reduced less impairment of spinal growth would occur. Furthermore, a more uniform approach to spinal irradiation should reduce the incidence of radiation induced gonadal damage.

\section{References}

1 Shalet SM. Disorders of the endocrine system due to radiation and cytotoxic chemotherapy. Clin Endocrinol (Oxf) 1983 (in press).

2 Rappaport R, Brauner R, Czernichow P, et al. Effect of hypothalamic and pituitary irradiation on pubertal development in children with cranial tumors. $J$ Clin Endocrinol Metab 1982; 54:1164-8.

3 Ahmed SR, Shalet SM, Campbell RHA, Deakin DP. Primary gonadal damage following treatment of brain tumours in childhood. J Pediatr 1983 (in press). 